\title{
Role of Molecular Profiling in Soft Tissue Sarcoma
}

\author{
Timothy Lindsay, MD, and Sujana Movva, $\mathrm{MD}^{\mathrm{b}}$
}

\section{Abstract}

Diagnosis and treatment of soft tissue sarcoma (STS) is a particularly daunting task, largely due to the profound heterogeneity that characterizes these malignancies. Molecular profiling has emerged as a useful tool to confirm histologic diagnoses and more accurately classify these malignancies. Recent large-scale, multiplatform analyses have begun the work of establishing a more complete understanding of molecular profiling in STS subtypes and to identify new molecular alterations that may guide the development of novel targeted therapies. This review provides a brief and general overview of the role that molecular profiling has in STS, highlighting select sarcoma subtypes that are notable for recent developments. The role of molecular profiling as it relates to diagnostic strategies is discussed, along with ways that molecular profiling may provide guidance for potential therapeutic interventions.

Soft tissue sarcoma (STS) is a diverse category of $>50$ distinct malignancies that pose many diagnostic and treatment-related challenges due to their remarkable heterogeneity. Molecular profiling has emerged as a useful tool for the mechanistic understanding, diagnosis, and therapeutics of STS, and continues to evolve at an exceptional pace. "Molecular profiling" often refers to in-depth analysis of DNA and RNA sequencing, as well as protein expression, which is the accepted definition used to frame this current review. In routine practice, fluorescence in situ hybridization (FISH) and reverse transcription-polymerase chain reaction (RT-PCR) are used to detect tumor-specific alterations, such as translocations, gene fusions, and amplifications. Immunohistochemistry (IHC) is also commonly used to detect loss or overexpression of proteins of interest (eg, DOG1 in gastrointestinal stromal tumors [GISTs]). Next-generation sequencing (NGS) of either DNA or RNA and gene expression profiling through microarray are being used as research tools to subclassify STS and identify therapeutic targets. The role of these newer techniques

aDepartment of Internal Medicine, Temple University Hospital, and bepartment of Medical Oncology and Hematology, Fox Chase Cancer Center, Philadelphia, Pennsylvania.

Submitted December 4, 2017; accepted for publication February 15, 2018.

Dr. Lindsay has disclosed that he has no financial interests, arrangements, affiliations, or commercial interests with the manufacturers of any in the daily clinical care of patients with STS is evolving and mostly remains investigational.

\section{Strategies for Diagnosis and Classification}

Traditionally, STSs have been diagnosed histologically through evaluating tumor grade and identifying tissue of origin. This pathologic diagnosis via light microscopy remains the gold standard. Molecular profiling, then, is often ordered as a companion test, especially when histologically based diagnoses are challenging. GENSARC $^{1}$ was a prospective observational study in which 384 patients had their tumors initially reviewed by expert pathologists solely based on histology and standardof-care IHC. Tumors were then rereviewed based on results from various molecular tests, including FISH, array comparative genomic hybridization, and RT-PCR. Of the 384 sarcomas, 53 (13.8\%) required diagnosis modification after the molecular results were available. Of the initial $43 \%$ of tumors for which diagnosis was certain at initial expert pathology review, $94 \%$ were confirmed molecularly.

products discussed in this article or their competitors. Dr. Movva has disclosed that she received research support from Takeda and Novartis Pharmaceuticals.

Correspondence: Sujana Movva, MD, Department of Medical Oncology and Hematology, Fox Chase Cancer Center, 333 Cottman Avenue, Philadelphia, PA 19111. Email: sujana.movva@fccc.edu 
Several large-scale studies have used multiplatform profiling technologies to examine STS and create detailed maps of molecular and biological markers across sarcoma subtypes (Table 1). It is evident that in general STSs have a low mutational burden, with TP53, ATRX, RB1, and BRCA2 representing some of the more commonly mutated genes across subtypes. More characteristically, STS is delineated by copy-number changes, chromosomal losses, or gene fusions. ${ }^{1-8}$
The Cancer Genome Atlas (TCGA) Research Network recently published data from a multiplatform analysis of 206 adult STSs, ${ }^{5}$ which consisted predominantly of leiomyosarcoma (LMS), dedifferentiated liposarcoma, and undifferentiated pleomorphic sarcoma (UPS), but also included myxofibrosarcoma (MFS), synovial sarcoma, and malignant peripheral nerve sheath tumors (MPNSTs). The complex genomic STSs were found to have more somatic copy-number alterations compared with other

\section{Table 1. Selected Large-Scale Analyses of Soft Tissue Sarcomas}

\begin{tabular}{|c|c|c|c|c|c|}
\hline Study & $\mathbf{N}$ & $\begin{array}{l}\text { Sarcoma } \\
\text { Subtypes }\end{array}$ & Techniques Used & Key Alterations & Special Comments \\
\hline $\begin{array}{l}\text { Italiano et al, } \\
2016\end{array}$ & 384 & 6 (soft tissue) & $\begin{array}{l}\text { IHC, aCGH, RT-PCR, } \\
\text { FISH, qPCR }\end{array}$ & $\begin{array}{l}T P 53, R B 1, P I K 3 C A, \\
\text { and } C D K N 2 A\end{array}$ & $\begin{array}{l}\text { Molecular profiling is necessary for accurate diagnosis. } \\
53 / 384(13.8 \%) \text { of diagnoses required modification } \\
\text { from histological diagnosis alone based on molecular } \\
\text { findings }\end{array}$ \\
\hline $\begin{array}{l}\text { Movva et al, } \\
2015\end{array}$ & 2,539 & $\begin{array}{l}61 \text { (bone and } \\
\text { soft tissue) }\end{array}$ & $\begin{array}{l}\text { IHC, FISH/CISH, } \\
\text { NGS, Sanger } \\
\text { sequence }\end{array}$ & $\begin{array}{l}\text { TP53 }(26.3 \%) \text { and } \\
\text { BRCA2 }(17.6 \%) \\
\text { mutations }\end{array}$ & DNA mutations identified in $47 \%$ of samples \\
\hline $\begin{array}{l}\text { Gounder et al, } \\
2017\end{array}$ & 5,749 & $\begin{array}{l}56 \text { (bone and } \\
\text { soft tissue) }\end{array}$ & NGS & $\begin{array}{l}\text { RB1 }(15.8 \%) \\
\text { CDKN2A }(17.2 \%) \\
\text { CDKN2B }(13.0 \%) \\
\text { CDK4 }(9.8 \%) \\
\text { MDM2 }(9.8 \%) \\
\text { ATRX }(8.7 \%) \\
\operatorname{KIT}(7.4 \%)\end{array}$ & Tumor mutational burden was 2.5/Mb (0-328) \\
\hline $\begin{array}{l}\text { The Cancer } \\
\text { Genome Atlas } \\
\text { Research } \\
\text { Network, }{ }^{5} 2017\end{array}$ & 206 & 6 (soft tissue) & $\begin{array}{l}\text { Whole-exome } \\
\text { and genome } \\
\text { sequencing, DNA } \\
\text { methylation, DNA } \\
\text { copy number, } \\
\text { telomere length, } \\
\text { mRNA expression } \\
\text { and mircroRNA- } \\
\text { based cluster } \\
\text { analysis, RPPA } \\
\text { analysis }\end{array}$ & $\begin{array}{l}\text { TP53, ATRX, and } \\
\text { RB1 mutations }\end{array}$ & $\begin{array}{l}\text { Low somatic mutation burden (average } 1.06 / \mathrm{Mb} \text { ); } \\
\text { more copy number alterations vs other tumors; } \\
\text { immune microenvironment signatures }\end{array}$ \\
\hline $\begin{array}{l}\text { Italiano et al, } \\
2017\end{array}$ & 587 & Multiple & NGS & $\begin{array}{l}\text { TP53 }(34.7 \%) \\
\text { ATRX }(9.1 \%) \\
\text { RB1 }(8.4 \%) \\
\text { KMT2D }(5.8 \%) \\
\text { NF1 }(5.3 \%) \\
\text { ATM }(5.1 \%) \\
\text { PI3KCA }(4.9 \%) \\
\text { ERBB4 }(4.2 \%) \\
\text { PTEN }(4 \%) \\
\text { ARID1A }(3.7 \%)\end{array}$ & $\begin{array}{l}\text { Most frequently amplified genes were } M D M 2(20 \%) \text {, } \\
\text { CDK4 }(16.7 \%), \text { GL1, MAP2KA, and TERT }(3.2 \% \text { for } \\
\text { each); most frequently deleted were RB1 }(12.7 \%) \text {, } \\
\text { CDKN2A }(10.3 \%), \text { CDKN2B }(9.7 \%), \text { TP53 }(9.5 \%), \text { PTEN } \\
(8.5 \%) ; 92.5 \% \text { of patients had at least one targetable } \\
\text { mutation, copy number alteration, and/or fusion gene }\end{array}$ \\
\hline $\begin{array}{l}\text { Barretina et } \\
\text { al, }{ }^{8} 2010\end{array}$ & 207 & 7 (soft tissue) & $\begin{array}{l}\text { DNA sequencing, } \\
\text { copy number } \\
\text { analysis, mRNA } \\
\text { expression } \\
\text { profiling }\end{array}$ & $\begin{array}{l}\text { KIT }(23 \% \text { of GIST); } \\
\text { PIK3CA ( } 18 \% \text { of } \\
\text { MRC); } \\
\text { TP53 }(16.7 \% \text { of } \\
\text { pleomorphic } \\
\text { sarcomas); } \\
\text { NF1 }(10.5 \% \text { of } \\
\text { MFS and } 8.3 \% \\
\text { of pleomorphic } \\
\text { sarcomas) }\end{array}$ & $\begin{array}{l}90 \% \text { amplification of chromosome } 12 q \text { in } \\
\text { dedifferentiated liposarcoma }\end{array}$ \\
\hline
\end{tabular}

Abbreviations: aCGH, array-comparative genomic hybridization; CISH, chromogenic in-situ hybridization; FISH, fluorescence in-situ hybridization; GIST, gastrointestinal stromal tumor; IHC, immunohistochemistry; MFS, myxofibrosarcoma; MRC, myxoid/round cell liposarcoma; NGS, nextgeneration sequencing; qPCR, quantitative polymerase chain reaction; RPPA, reverse phase protein array; RT-PCR, reverse-transcription polymerase chain reaction. 
Lindsay and Movva

TCGA tumor types, and the overall somatic mutation burden was low, averaging only 1.06 per $\mathrm{Mb}$. In this and other series, molecular profiling has also been used to subclassify more common STS, such as LMS, either biologically or prognostically. ${ }^{1,9-11}$

A broad subset of STSs remains classified under the nonspecific umbrellas of UPS or sarcomas not otherwise specified (NOS). Using microarray data, Konstantinopoulos et $\mathrm{a}^{12}$ reclassified $76 \mathrm{ma}$ lignant fibrous histiocytomas (MFHs) and 10 NOS tumors using a 170-gene signature. Although the term "MFH" has since been abandoned, 3 of the 10 NOS tumors were predicted to be liposarcoma, with 3 predicted as LMS and 1 as fibrosarcoma. After unsupervised hierarchical clustering, 6 of the 10 NOS samples (60\%) were found clustered with their predicted subtype, providing support for molecular profiling in reclassification of these heterogenous categories. Others have performed similar work, ${ }^{13-15}$ and future studies may continue to more appropriately classify these undifferentiated tumors. Interestingly, in the TCGA data set, ${ }^{5} \mathrm{MFS}$, which was more recently separated from UPS on clinicopathologic grounds, had a very similar molecular profile to UPS, suggesting that UPS and MFS may exist instead as a spectrum of the same disease. The investigators ${ }^{5}$ postulated that the similarities may have been due to the fact that approximately $65 \%$ of the samples were nonclassic MFS, including high-grade epithelioid tumors. The role that molecular profiling has played in the diagnosis and classification of selected STS subtypes is discussed herein.

\section{Small Blue Round Cell Tumors}

Undifferentiated round cell sarcomas, although lacking the characteristic EWS-ETS translocation of Ewing sarcoma, have in general been treated as such. Recently, the identification of CIC and BCOR fusion proteins has shown promise in helping to unify these Ewing-like small blue round cell tumors (SBRCTs).

Selecting from a population of patients with EWSR1 - and FUS-negative SBRCTs, Antonescu et $\mathrm{al}^{16}$ identified a study cohort of 115 patients over a 20-year history with a CIC gene break-apart signal; $57 \%$ were positive for fusion to DUX4 genes, either at $4 \mathrm{q} 35(35 \%)$ or $10 \mathrm{q} 26(22 \%)$. In this cohort, CIC-rearranged tumors predominantly arose from the soft tissue (86\%). Compared with an Ewing sarcoma cohort, these tumors had a higher metastasis rate and patients were older and had a significantly reduced overall survival (43\% vs $79 \%$ at 5 years), matched for stage and age $(P=.002)$. Other studies and case reports have also noted a connection between CIC-fusion and undifferentiated Ewing-like round cell sarcomas. ${ }^{17-19}$ Importantly, another study demonstrated that CIC break-apart FISH assays can miss a significant minority of CIC-DUX4 SBRCTs (estimated as up to $14 \%$ ). RNA sequencing revealed CIC-fusion transcripts in these cases, reinforcing that FISH analysis should be used cautiously as only an adjunct to morphologic and IHC assessment, which remain the diagnostic standards. ${ }^{20}$

Another subset of Ewing-like SBRCTs consists of a fusion protein between $\mathrm{BCOR}$ and $\mathrm{CCNB} 3$. Although most of these sarcomas harboring the BCORCCNB3 gene fusion arise in bone, a subset are soft tissue tumors. BCOR-CCNB3 fusions have been found in various series of undifferentiated, unclassified sarcomas, including those from soft tissue, with a predilection for male patients. ${ }^{21,22}$ Other BCOR fusion partners include MAML3 and $2 \mathrm{C} 3 \mathrm{H} 7 \mathrm{~B}$, and they have again been detected predominantly in male patients with both bone and soft tissue tumors, appearing to have an aggressive clinical course. ${ }^{23}$

\section{Gastrointestinal Stromal Tumors}

Among STSs, GISTs are often used as the archetypes for the utility of molecular profiling. Historically, limited panels using a small number of genes have been used. It has already been described at length that the gain-of-function mutation in the oncogenic receptor tyrosine kinase protein "KIT" is seen in $>80 \%$ of GISTs and serves as a universal therapeutic target in KIT-containing GISTs. ${ }^{24-26}$

Within the remaining approximately $15 \%$ of KIT/PDGFRA wild-type GISTs (WT-GISTs), however, several new subtypes have been characterized, including SDH, NF1, and BRAF/k-RAS-associated GIST. ${ }^{27,28}$ SDH-deficient GISTs constitute $>80 \%$ of KIT/PDGFRA WT-GISTs ${ }^{29}$ and can occur either as part of a syndrome (eg, Carney triad) or sporadically. These GISTs are epithelioid or mixed in morphology and appear to be poorly responsive to tyrosine kinase inhibitor therapies. ${ }^{30} \mathrm{NF} 1$-associated GISTs tend to be multifocal with spindle-cell morphology and are typically less responsive to imatinib therapy. ${ }^{31}$ Finally, up to $13 \%$ of WT-GISTs have been found to have mutations in exon 15 of BRAF. These also 
have a spindle cell morphology, and are driven by a substitution of V600E on exon 15, which activates the kinase domain of BRAF and results in KIT-independent growth. This substitution is thought to mediate the imatinib-resistance commonly seen in these BRAF/k-RAS-associated GISTs. . $^{2,32-35}$

There remains a small subset of GISTs lacking the aforementioned canonical mutations, which are often referred to as "quadruple-WT-GISTs" (qWT-GISTs). Molecular profiling has allowed for further characterization of these qWT-GISTs, however, and some have argued that "WT-GIST" is a misnomer, because recent analyses have identified at least 9 other distinct driver mutations. ${ }^{36}$ Newly identified alterations in these socalled qWT-GISTs include neurotrophic tropomyosin receptor and cyclin-dependent kinases (NTRK and CDK6), the ETS-transcription factor ERG, and fibroblast growth factor receptor FGFR1, along with LTK, PARK2, SUFU, and others. ${ }^{28,29,37}$

The identification of an NTRK alteration in qWT-GISTs is particularly important because of new molecularly directed therapies that are currently under investigation. The NTRK gene fusion, in this case, of ETV6-NTRK3 results in irreversible activation of IGF1R with sustained cell survival through the Ras-Erk1/2 and PI3K-Akt pathways and serves as a potential therapeutic target for this GIST subtype with NTRK inhibitors, such as larotrectinib or entrectinib. 37,38

\section{Epithelioid Sarcoma}

Both the distal and proximal types of epithelioid sarcoma have been shown to exhibit alterations in the SMARCB1/INI-1 gene on chromosome 22q. $\cdot^{39,40}$ It appears that deletion of the tumor suppressor SMARCB1/INI-1 occurs in $45 \%$ to $90 \%$ of cases of epithelioid sarcoma, which results in a loss of the functional protein SMARCB1/INI-1 in the SWI/SNF complex. ${ }^{39,41,42}$ INI-1 is a component of SMARCB1, which is a subunit of the SWI/SNF complex, which in turn serves as an ATP-dependent agent of chromatin remodeling and activates gene transcription through epigenetic changes. ${ }^{43}$ Loss of INI-1 expression by IHC has been seen in $>90 \%$ of epithelioid sarcomas ${ }^{40}$ and IHC demonstration of INI-1 loss is considered a molecular hallmark of diagnosis in epithelioid sarcoma.

Importantly, INI-1 loss is not unique to epithelioid sarcoma. A loss of SMARCB1/INI-1 expression has also been shown in malignant rhabdoid tumors, as well as renal medullary carcinomas, epithelioid MPNSTs, and others. ${ }^{43-45}$ This lends further support for the importance of clinical and histologic assessment as a cornerstone of the diagnostic process.

\section{Strategies for Therapy}

The utility of molecular profiling to direct therapy in patients with refractory disease has been studied extensively. In a recent series of 107 patients whose tumors were interrogated on a 405-gene panel for DNA and 265-gene panel for RNA, 57\% had at least one treatment-linked alteration. Notably, NGS changed the initial diagnosis and resulting treatments in $5 \%$ of patients (eg, LMS to liposarcoma). ${ }^{4}$ In another study of 102 patients who had profiling on a 236- or 315gene panel, $61 \%$ were considered to have an actionable mutation and $16 \%$ were able to be treated with targeted therapy. ${ }^{46}$ It is important to note that "actionable" in this particular study was loosely defined as "any gene alteration that is either directly targeted or a pathway component of a directly targeted gene by an approved or investigational drug." Nonetheless, there are ongoing developments to use information from molecular profiling to direct new and investigational therapies (see next section), and results from recent molecular-based trials are highlighted in Table 2. Several specific STSs have been selected for further discussion.

\section{CDK4 Inhibitors in Liposarcoma}

Liposarcoma, one of the most common STSs, is classified into several types: well-differentiated/dedifferentiated, myxoid/round cell, and pleomorphic liposarcoma. Although the treatment strategy for all of these is typically surgical, finding a successful targeted therapy for well-differentiated/dedifferentiated liposarcoma is of particular interest in the setting of recurrent disease. ${ }^{47}$

From a molecular standpoint, both well-differentiated and dedifferentiated liposarcoma are characterized by amplification of regions of chromosome 12q13-15 containing the MDM2 and CDK4 genes, demonstrated in $>90 \%$ of cases. ${ }^{48,49}$ Palbociclib, ribociclib, and abemaciclib are cyclin-dependent kinase inhibitors that are FDA-approved for postmenopausal patients with metastatic breast cancer..$^{50}$ As such, naturally, their utility in the treatment of liposarcoma has been explored. 
Lindsay and Movva

\section{Table 2. Selected Studies With Molecular Profiling as a Guide for Therapy}

\begin{tabular}{|c|c|c|c|c|c|}
\hline Study & $\mathbf{N}$ & $\begin{array}{l}\text { Sarcoma } \\
\text { Subtypes }\end{array}$ & Molecular Target & Targeted Therapy & Results \\
\hline 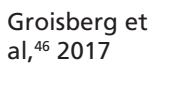 & 102 & Multiple & Multiple & Multiple & $\begin{array}{l}61 \% \text { with potentially actionable alteration. Of the } \\
\text { entire cohort, } 58 \% \text { chose to participate in a trial; } 16 \% \\
\text { received matched therapy and } 50 \% \text { of these had SD }\end{array}$ \\
\hline $\begin{array}{l}\text { Dickson et al, }{ }^{52} \\
2016\end{array}$ & 60 & $\begin{array}{l}\text { Well- } \\
\text { differentiated, } \\
\text { dedifferentiated } \\
\text { LPS }\end{array}$ & $C D K 4$ & Palbociclib & CR $(n=1), P R(n=1) ; 57.2 \%$ PFS at 12 weeks \\
\hline $\begin{array}{l}\text { Ray-Coquard } \\
\text { et al, }{ }^{53} 2012\end{array}$ & 20 & $\begin{array}{l}\text { Well- } \\
\text { differentiated, } \\
\text { dedifferentiated } \\
\text { LPS }\end{array}$ & MDM2 & $\begin{array}{l}\text { RG7112 (MDM2- } \\
\text { inhibitor) }\end{array}$ & $\begin{array}{l}P R(n=1), S D(n=14), P D(n=5 \text {, all dedifferentiated LPS) } \\
\text { prior to surgical resection }\end{array}$ \\
\hline $\begin{array}{l}\text { Gounder et } \\
\text { al, }{ }^{59} 2017\end{array}$ & 31 & $\begin{array}{l}\text { Epithelioid } \\
\text { sarcoma }\end{array}$ & $E Z H 2$ & Tazemetostat & PR in 4 patients, SD $\geq 32$ weeks in 6 patients \\
\hline $\begin{array}{l}\text { Schoffski et } \\
\text { al, }{ }^{60} 2017\end{array}$ & 33 & Synovial sarcoma & $E Z H 2$ & Tazemetostat & $\begin{array}{l}\text { SD in } 10 \text { patients ( } 30 \%) \text {, lasting } \geq 16 \text { weeks in } 5 \\
\text { patients }(15 \%)\end{array}$ \\
\hline $\begin{array}{l}\text { Hyman et al, }{ }^{64} \\
2017\end{array}$ & 55 & $\begin{array}{l}\text { TRK fusion- } \\
\text { positive tumors, } \\
\text { including } \\
\text { sarcomas }\end{array}$ & $\begin{array}{l}\text { NTRK1 (25) } \\
\text { NTRK2 (1) } \\
\text { NTRK3 (29) }\end{array}$ & Larotrectinib & $\begin{array}{l}\text { Patient with GIST with ongoing PR at } 4 \text { months; other } \\
\text { STS-specific data unknown }\end{array}$ \\
\hline
\end{tabular}

Abbreviations: CR, complete response; GIST, gastrointestinal stromal tumor; LPS, liposarcoma; PD, progressive disease; PFS, progression-free survival; $\mathrm{PR}$, partial response; SD, stable disease; STS, soft tissue sarcoma.

Two phase II, nonrandomized, open-label clinical trials have demonstrated significant and favorable responses to CKD4 inhibition. In the original study, ${ }^{51} 30$ patients were treated with palbociclib. Of the tumors screened, 92\% demonstrated CDK4 amplification. Of the 29 evaluable patients, 19 were progression-free at 12 weeks (66\%), which compared favorably with an expected progression-free survival (PFS) rate of $40 \%$. Median PFS was 17.9 weeks. In a follow-up study using an alternate dosing schedule, there was a 12 -week PFS rate of $57.2 \%$ and a median PFS of 17.9 weeks in the 57 evaluable patients. ${ }^{51,52}$ These are among the first trials to date to specifically use targeted molecular therapy in liposarcoma.

The initial trials of MDM2 antagonists were beleaguered by severe toxicities, but showed a favorable effect on tumor progression..$^{53}$ Further research in vitro and in xenograft models have shown continued promise and a potential modulatory effect of MDM2 on CDK4 and synergy with PI3k/mTOR pathways. ${ }^{54,55}$ Attempts to make these agents more tolerable are underway. ${ }^{46}$

\section{EZH2 Inhibitors in Epithelioid Sarcoma and Synovial Sarcoma}

EZH2 inhibition has shown promise as a new potential molecular target for therapy. EZH2 is the catalytic subunit of the polycomb repressive complex 2
(PRC2), a multiprotein complex responsible for the methylation of chromatin and repression of gene expression. This complex antagonizes the work of SWI/ SNF, which is often rendered ineffective by alterations in the SMARCB1 subunit, as previously discussed. ${ }^{56}$ Recent in vivo and xenograft studies have supported the theory that EZH2-mediated activity of PRC2 may be an attractive therapeutic target, demonstrating inhibition of cell growth and migration in synovial sarcoma lines to EZH2 inhibition. ${ }^{57,58}$ Clinical trials have now begun, and preliminary data for tazemetostat, a potent and selective EZH2 inhibitor, has shown guarded promise.

Gounder et al $^{59}$ recently released preliminary data from a phase II multicenter study of tazemetostat in adults with INI1-negative sarcoma (ClinicalTrials.gov identifier: NCT02601950). Results from participants with epithelioid sarcoma have been notably positive. Although the final data are still pending, of the 31 patients with a median of one prior systemic therapy exposure, 4 (13\%) have shown a partial response and $6(32 \%)$ have exhibited stable disease at $\geq 32$ weeks.

Conversely, Schoffski et a ${ }^{60}$ presented less promising preliminary data from the synovial sarcoma cohort in the same trial: of the 33 patients treated with tazemetostat, although 30\% exhibited stable disease at 16 weeks, it lasted $>16$ weeks in only $15 \%$. No ob- 
jective responses were seen in the synovial sarcoma cohort, and therefore tazemetostat was not considered to be clinically active in this cohort. Synovial sarcoma is defined by a specific chromosomal translocation resulting in an SS18-SSX fusion oncogene. This fusion protein competes with SMARCB1 for incorporation into the SWI/SNF complex assembly, which is thought to promote oncogenesis through functional instability of the SWI/SNF complex. ${ }^{61,62}$ A recent report showed that recruitment of SWI/SNF complexes to polycomb-silenced chromatin leads to polycomb eviction and loss of histone-association with transcriptional repression. ${ }^{63} \mathrm{SWI} / \mathrm{SNF}$ complexes without SMARCB1, as seen in epithelioid sarcoma, cannot evict polycomb, which leaves the repressive modifications in place. However, in tumors like synovial sarcoma, the SWI/SNF complex may be able to evict polycomb because of the incorporation of SS18-SSX in the SWI/SNF complex. This may lead to a loss of the repressive histone modifications and, in turn, activate expression of the SOX2 gene and drive proliferation. This model may explain why no patients with synovial sarcoma derived a response from tazemetostat. In both the synovial sarcoma and epithelioid sarcoma cohorts, the rate of grade $\geq 3$ adverse events was low and there were no treatment discontinuations due to adverse events.

\section{NTRK3 as a New Target in WT-GIST and Other STSs}

NTRK3 has recently been identified as a therapeutic target in qWT-GISTs and other STSs. ${ }^{37}$ The Trk receptor family includes 3 transmembrane protein receptors that are encoded by the NTRK1, NTRK2, and NTRK3 genes. Alterations in NTRK genes occur in a variety of tumors, albeit in most at a low frequency, and lead to a constitutively activated kinase that confers oncogenic potential. Larotrectinib, a selective pan-TRK inhibitor, has been recently studied in phase I trials. A review of the data sets for 3 of these studies included 10 patients with sarcoma and 2 with GIST. NTRK alterations were detected across the studies using NGS, FISH, and IHC. Sarcoma subtypes included infantile fibrosarcoma, sarcoma NOS, and MPNST. Responses were seen across tumor types regardless of NTRK gene type or fusion partner, with an overall objective response rate of $78 \%$, including a patient with GIST who had an ongoing partial response at 4 months. ${ }^{64}$ The most common treatment-emergent adverse events were fatigue, dizziness, and nausea.

\section{Predictive Biomarkers for Immune Checkpoint Inhibition}

Immune checkpoint inhibitors such as anti-PD-1, anti-PD-L1, and anti-CTLA-4 antibodies have recently gained interest as potential therapeutic options in STS. Results have been mixed overall, with some response noted in UPS and dedifferentiated liposarcoma with the anti-PD-1 antibody pembrolizumab, ${ }^{65}$ but not in uterine LMS using another PD-1 inhibitor, nivolumab, ${ }^{66}$ or in synovial sarcoma using the anti-CTLA-4 antibody ipilimumab. ${ }^{67}$ The exact factors that mediate activity in some STSs versus others are still under investigation, but the differing immune microenvironment of sarcoma subtypes may play a role. Pollack et $\mathrm{al}^{68}$ recently found that high-grade sarcomas such as UPS had higher levels of genes related to antigen expression, high TCR clonality, and high PD-1 and PD-L1 expression. Contrary to the poor clinical activity of nivolumab in LMS, the specimens analyzed in this series also appeared to fit the pattern of an inflammatory tumor type similar to UPS.

Many studies have examined the expression of PD-1 and PD-L1 in sarcoma subtypes. ${ }^{2,69,70}$ However, expression through IHC has been inconsistent across studies, likely due to variability in antibodies and cutoff points. ${ }^{71}$ Indeed, in the study of pembrolizumab in STS, PD-L1 expression was positive at the $1 \%$ threshold in only 3 pretreatment samples $(4 \%) .{ }^{65}$ Notably, all 3 patients had UPS; however, reliable correlations between response and PD-L1 expression cannot be made in this series. It has been proposed that high mutational burden identified through NGS may serve as a positive predictive factor for immune checkpoint inhibition ${ }^{71}$ based on the experience in other malignancies, such as melanoma ${ }^{72}$ and nonsmall cell lung cancer. ${ }^{73}$ The field of NGS in STS, however, is still developing and mutational burden as a predictor of immunotherapy response has not yet been investigated.

\section{Implications for the Future}

Molecular profiling in STS, with its implications for diagnosis and therapeutic interventions, continues 
to progress rapidly. These techniques are becoming increasingly important in confirmation of diagnosis and sarcoma subtype refinement. Large genomic databases continue to investigate these rare diseases and identify new potential treatment approaches, such as newer generation TORC1/TORC2 inhibitors in LMS. ${ }^{5}$ Genomic biomarkers for response to immunotherapy in STS will also be helpful as the field continues to move forward. Other ongoing initiatives include the MULTISARC phase III precision medicine trial, ${ }^{6}$ in which patients with doxorubicin-refractory STS will be randomized to standard-of-care treatment or treatment based on genomic profiling. Diagnosis and treatment of sarcoma is evolving rapidly, and an intimate knowledge of molecular profiling is essential to the understanding and further development of the field.

\section{References}

1. Italiano A, Di Mauro I, Rapp J, et al. Clinical effect of molecular methods in sarcoma diagnosis (GENSARC): a prospective, multicentre, observational study. Lancet Oncol 2016;17:532-538.

2. Movva S, Wen W, Chen W, et al. Multi-platform profiling of over 2000 sarcomas: identification of biomarkers and novel therapeutic targets. Oncotarget 2015;6:12234-12247.

3. Agaram NP, Zhang L, LeLoarer F, et al. Targeted exome sequencing profiles genetic alterations in leiomyosarcoma. Genes Chromosomes Cancer 2016;55:124-130.

4. Gounder MM, Ali SM, Robinson V, et al. Impact of next-generation sequencing (NGS) on diagnostic and therapeutic options in soft-tissue and bone sarcoma [abstract]. J Clin Oncol 2017;35(Suppl):Abstract 11001.

5. The Cancer Genome Atlas Research Network. Comprehensive and integrated genomic characterization of adult soft tissue sarcomas. Cell 2017;171:950-965.e28.

6. Italiano A, Khalifa E, Laizet Y, et al. Genetic landscape of soft-tissue sarcomas: moving toward personalized medicine [abstract]. J Clin Oncol 2017;35(Suppl):Abstract 11002 .

7. Jour G, Scarborough JD, Jones RL, et al. Molecular profiling of soft tissue sarcomas using next-generation sequencing: a pilot study toward precision therapeutics. Hum Pathol 2014;45:1563-1571.

8. Barretina J, Taylor BS, Banerji S, et al. Subtype-specific genomic alterations define new targets for soft-tissue sarcoma therapy. Nat Genet 2010;42:715-721.

9. Skubitz KM, Skubitz AP. Differential gene expression in leiomyosarcoma. Cancer 2003;98:1029-1038.

10. Beck AH, Lee $\mathrm{CH}$, Witten DM, et al. Discovery of molecular subtypes in leiomyosarcoma through integrative molecular profiling. Oncogene 2010;29:845-854.

11. Guo X, Jo VY, Mills AM, et al. Clinically relevant molecular subtypes in leiomyosarcoma. Clin Cancer Res 2015;21:3501-3511.

12. Konstantinopoulos PA, Fountzilas E, Goldsmith JD, et al. Analysis of multiple sarcoma expression datasets: implications for classification, oncogenic pathway activation and chemotherapy resistance. PLoS One 2010;5:e9747.

13. Baird K, Davis S, Antonescu CR, et al. Gene expression profiling of human sarcomas: insights into sarcoma biology. Cancer Res 2005;65:9226-9235.

14. Mertens F, Fletcher CD, Dal Cin P, et al. Cytogenetic analysis of 46 pleomorphic soft tissue sarcomas and correlation with morphologic and clinical features: a report of the CHAMP study group. Chromosomes and MorPhology. Genes Chromosomes Cancer 1998;22:16-25.

15. Hofvander J, Tayebwa J, Nilsson J, et al. Recurrent PRDM10 gene fusions in undifferentiated pleomorphic sarcoma. Clin Cancer Res 2015;21:864869.

16. Antonescu CR, Owosho AA, Zhang L, et al. Sarcomas with CICrearrangements are a distinct pathologic entity with aggressive outcome: a clinicopathologic and molecular study of 115 cases. Am J Surg Pathol 2017;41:941-949.

17. Yoshimoto T, Tanaka M, Homme M, et al. CIC-DUX4 induces small round cell sarcomas distinct from Ewing sarcoma. Cancer Res 2017;77:29272937.

18. Italiano A, Sung YS, Zhang L, et al. High prevalence of CIC fusion with double-homeobox (DUX4) transcription factors in EWSR1-negative undifferentiated small blue round cell sarcomas. Genes Chromosomes Cancer 2012;51:207-218.
19. Choi EY, Thomas DG, McHugh JB, et al. Undifferentiated small round cell sarcoma with $\mathrm{t}(4 ; 19)(\mathrm{q} 35 ; \mathrm{q} 13.1)$ CIC-DUX4 fusion: a novel highly aggressive soft tissue tumor with distinctive histopathology. Am J Surg Pathol 2013;37:1379-1386.

20. Yoshida A, Arai Y, Kobayashi E, et al. CIC break-apart fluorescence in-situ hybridization misses a subset of CIC-DUX4 sarcomas: a clinicopathological and molecular study. Histopathology 2017;71:461-469.

21. Kao YC, Sung YS, Zhang L, et al. BCOR overexpression is a highly sensitive marker in round cell sarcomas with BCOR genetic abnormalities. Am J Surg Pathol 2016;40:1670-1678.

22. Matsuyama A, Shiba E, Umekita Y, et al. Clinicopathologic diversity of undifferentiated sarcoma with BCOR-CCNB3 fusion. Am J Surg Pathol 2017;41:1713-1721.

23. Specht K, Zhang L, Sung YS, et al. Novel BCOR-MAML3 and ZC3H7B $\mathrm{BCOR}$ gene fusions in undifferentiated small blue round cell sarcomas. Am J Surg Pathol 2016;40:433-442.

24. Norberg SM, Movva S. Role of genetic and molecular profiling in sarcomas Curr Treat Options Oncol 2015;16:24

25. Hirota S, Isozaki K, Moriyama Y, et al. Gain-of-function mutations of c-kit in human gastrointestinal stromal tumors. Science 1998;279:577-580.

26. Rubin BP, Singer $S$, Tsao C, et al. KIT activation is a ubiquitous feature of gastrointestinal stromal tumors. Cancer Res 2001;61:8118-8121.

27. Doyle LA, Hornick JL. Gastrointestinal stromal tumours: from KIT to succinate dehydrogenase. Histopathology 2014;64:53-67.

28. Nannini $M$, Astolfi $A$, Urbini $M$, et al. Integrated genomic study of quadruple-WT GIST (KIT/PDGFRA/SDH/RAS pathway wild-type GIST). BMC Cancer 2014;14:685.

29. Boikos SA, Pappo AS, Killian JK, et al. Molecular subtypes of KIT/ PDGFRA wild-type gastrointestinal stromal tumors: a report from the National Institutes of Health Gastrointestinal Stromal Tumor Clinic. JAMA Oncol 2016;2:922-928.

30. Mason EF, Hornick JL. Conventional risk stratification fails to predict progression of succinate dehydrogenase-deficient gastrointestinal stromal tumors. Am J Surg Pathol 2016;40:1616-1621.

31. Gasparotto D, Rossi S, Polano M, et al. Quadruple-negative GIST is a sentinel for unrecognized neurofibromatosis type 1 syndrome. Clin Cancer Res 2017;23:273-282

32. Agaimy A, Terracciano LM, Dirnhofer $S$, et al. V600E BRAF mutations are alternative early molecular events in a subset of KIT/PDGFRA wild type gastrointestinal stromal tumours. J Clin Pathol 2009;62:613-616.

33. Hostein I, Faur N, Primois C, et al. BRAF mutation status in gastrointestinal stromal tumors. Am J Clin Pathol 2010;133:141-148.

34. Agaram NP, Wong GC, Guo T, et al. Novel V600E BRAF mutations in imatinib-naive and imatinib-resistant gastrointestinal stromal tumors. Genes Chromosomes Cancer 2008;47:853-859.

35. Rossi S, Sbaraglia M, Dell'Orto MC, et al. Concomitant KIT/BRAF and PDGFRA/BRAF mutations are rare events in gastrointestinal stromal tumors. Oncotarget 2016;7:30109-30118.

36. Alkhuziem M, Burgoyne AM, Fanta PT, et al. The call of "the wild"-type GIST: it's time for domestication. J Natl Compr Canc Netw 2017;15:551 554

37. Shi E, Chmielecki J, Tang CM, et al. FGFR1 and NTRK3 actionable alterations in 'wild-type' gastrointestinal stromal tumors. J Transl Med 2016;14:339.

38. Brenca M, Rossi S, Polano M, et al. Transcriptome sequencing identifies ETV6-NTRK3 as a gene fusion involved in GIST. J Pathol 2016;238:543549. 
39. Modena P, Lualdi E, Facchinetti F, et al. SMARCB1/INI1 tumor suppressor gene is frequently inactivated in epithelioid sarcomas. Cancer Res 2005;65:4012-4019.

40. Hornick JL, Dal Cin P, Fletcher CD. Loss of INI1 expression is characteristic of both conventional and proximal-type epithelioid sarcoma. Am J Surg Pathol 2009;33:542-550.

41. Sullivan LM, Folpe AL, Pawel BR, et al. Epithelioid sarcoma is associated with a high percentage of SMARCB1 deletions. Mod Pathol 2013;26:385_ 392.

42. Le Loarer F, Zhang L, Fletcher CD, et al. Consistent SMARCB1 homozygous deletions in epithelioid sarcoma and in a subset of myoepithelial carcinomas can be reliably detected by FISH in archival material. Genes Chromosomes Cancer 2014;53:475-486.

43. Hollmann TJ, Hornick JL. INI1-deficient tumors: diagnostic features and molecular genetics. Am J Surg Pathol 2011;35;e47-63.

44. Kohashi K, Oda $\mathrm{Y}$, Yamamoto $\mathrm{H}$, et al. Highly aggressive behavior of malignant rhabdoid tumor: a special reference to SMARCB1/INI1 gene alterations using molecular genetic analysis including quantitative realtime PCR. J Cancer Res Clin Oncol 2007;133:817-824.

45. Kohashi K, Yamada Y, Hotokebuchi Y, et al. ERG and SALL4 expressions in SMARCB1/INI1-deficient tumors: a useful tool for distinguishing epithelioid sarcoma from malignant rhabdoid tumor. Hum Pathol 2015;46:225-230.

46. Groisberg R, Hong DS, Holla V, et al. Clinical genomic profiling to identify actionable alterations for investigational therapies in patients with diverse sarcomas. Oncotarget 2017;8:39254-39267

47. Crago AM, Dickson MA. Liposarcoma. Surg Oncol Clin N Am 2016;25:761-773.

48. Sirvent N, Coindre JM, Maire G, et al. Detection of MDM2-CDK4 amplification by fluorescence in situ hybridization in 200 paraffinembedded tumor samples: utility in diagnosing adipocytic lesions and comparison with immunohistochemistry and real-time PCR. Am J Surg Pathol 2007;31:1476-1489.

49. Singer S, Socci ND, Ambrosini G, et al. Gene expression profiling of liposarcoma identifies distinct biological types/subtypes and potential therapeutic targets in well-differentiated and dedifferentiated liposarcoma. Cancer Res 2007;67:6626-6636.

50. Kwapisz D. Cyclin-dependent kinase $4 / 6$ inhibitors in breast cancer: palbociclib, ribociclib, and abemaciclib. Breast Cancer Res Treat 2017;166:41-54.

51. Dickson MA, Tap WD, Keohan ML, et al. Phase II trial of the CDK4 inhibitor PD0332991 in patients with advanced CDK4-amplified welldifferentiated or dedifferentiated liposarcoma. J Clin Oncol 2013;31:2024 2028.

52. Dickson MA, Schwartz GK, Keohan ML, et al. Progression-free survival among patients with well-differentiated or dedifferentiated liposarcoma treated with CDK4 inhibitor palbociclib: a phase 2 clinical trial. JAMA Oncol 2016;2:937-940.

53. Ray-Coquard I, Blay JY, Italiano A, et al. Effect of the MDM2 antagonist RG7112 on the P53 pathway in patients with MDM2-amplified, welldifferentiated or dedifferentiated liposarcoma: an exploratory proof-ofmechanism study. Lancet Oncol 2012;13:1133-1140.

54. Kovatcheva M, Liu DD, Dickson MA, et al. MDM 2 turnover and expression of ATRX determine the choice between quiescence and senescence in response to CDK4 inhibition. Oncotarget 2015;6:8226-8243.
55. Laroche A, Chaire V, Algeo MP, et al. MDM2 antagonists synergize with $\mathrm{PI} 3 \mathrm{~K} / \mathrm{mTOR}$ inhibition in well-differentiated/dedifferentiated liposarcomas. Oncotarget 2017;8:53968-53977.

56. Wilson BG, Wang $X$, Shen $X$, et al. Epigenetic antagonism between polycomb and SWI/SNF complexes during oncogenic transformation. Cancer Cell 2010;18:316-328.

57. Shen JK, Cote GM, Gao Y, et al. Targeting EZH2-mediated methylation of H3K27 inhibits proliferation and migration of synovial sarcoma in vitro. Sci Rep 2016;6:25239.

58. Kawano S, Grassian AR, Tsuda M, et al. Preclinical evidence of anti-tumor activity induced by EZH2 inhibition in human models of synovial sarcoma. PLoS One 2016;11:e0158888.

59. Gounder MM, Stacchiotti S, Schöffski P, et al. Phase 2 multicenter study of the EZH2 inhibitor tazemetostat in adults with INI1 negative epithelioid sarcoma (NCT02601950) [abstract]. J Clin Oncol 2017;35(Suppl):Abstract 11058.

60. Schoffski P, Agulnik M, Stacchiotti S, et al. Phase 2 multicenter study of the EZH2 inhibitor tazemetostat in adults with synovial sarcoma (NCT02601950) [abstract]. J Clin Oncol 2017;35(Suppl):Abstract 11057.

61. Kadoch C, Crabtree GR. Reversible disruption of mSWI/SNF (BAF) complexes by the SS18-SSX oncogenic fusion in synovial sarcoma. Cell 2013;153:71-85.

62. Nielsen TO, Poulin NM, Ladanyi M. Synovial sarcoma: recent discoveries as a roadmap to new avenues for therapy. Cancer Discov 2015;5:124-134.

63. Lu C, Allis CD. SWI/SNF complex in cancer. Nat Genet 2017;49:178179.

64. Hyman DM, Laetsch TW, Kummar S, et al. The efficacy of larotrectinib (LOXO-101), a selective tropomyosin receptor kinase (TRK) inhibitor, in adult and pediatric TRK fusion cancers [abstract]. J Clin Oncol 2017;35(Suppl):Abstract LBA2501.

65. Tawbi HA, Burgess M, Bolejack V, et al. Pembrolizumab in advanced softtissue sarcoma and bone sarcoma (SARC028): a multicentre, two-cohort, single-arm, open-label, phase 2 trial. Lancet Oncol 2017;18:1493-1501.

66. Ben-Ami E, Barysauskas CM, Solomon S, et al. Immunotherapy with single agent nivolumab for advanced leiomyosarcoma of the uterus: results of a phase 2 study. Cancer 2017;123:3285-3290.

67. Maki RG, Jungbluth AA, Gnjatic S, et al. A pilot study of anti-CTLA4 antibody ipilimumab in patients with synovial sarcoma. Sarcoma 2013;2013:168145.

68. Pollack SM, He Q, Yearley JH, et al. T-cell infiltration and clonality correlate with programmed cell death protein 1 and programmed death-ligand 1 expression in patients with soft tissue sarcomas. Cancer 2017;123:3291-3304.

69. Kim JR, Moon YJ, Kwon KS, et al. Tumor infiltrating PD1-positive lymphocytes and the expression of PD-L1 predict poor prognosis of soft tissue sarcomas. PLoS One 2013;8:e82870.

70. Kim C, Kim EK, Jung H, et al. Prognostic implications of PD-L1 expression in patients with soft tissue sarcoma. BMC Cancer 2016;16:434.

71. Veenstra R, Kostine M, Cleton-Jansen AM, et al. Immune checkpoint inhibitors in sarcomas: in quest of predictive biomarkers. Lab Investig 2018;98:41-50.

72. Snyder A, Makarov V, Merghoub T, et al. Genetic basis for clinical response to CTLA-4 blockade in melanoma. N Engl J Med 2014;371:2189-2199.

73. Rizvi NA, Hellmann MD, Snyder A, et al. Mutational landscape determines sensitivity to PD-1 blockade in non-small cell lung cancer. Science 2015;348:124-128. 